\title{
Effect of Cloud Computing on Enterprises: A Review
}

\author{
Shikha Dixit \\ Research Scholar \\ Sai Nath University
}

\author{
Ashutosh Sharma, Ph.D. \\ Principal \\ Globus Engineering College
}

\begin{abstract}
Innovations are supreme to ride the spontaneous tide of change. Worst talented of enterprises are event to trim their computing jurisdiction look go away from the means of virtualization. This fondness of reducing the computing cost has led to the innovation of Unsympathetic Computing. Tarnish Computing offers rectify computing through wiser utilization and reduced administration and infrastructure costs. Allay Computing is the go on increase of Software as a Service (SaaS) and Benefit Computing. Narcotize Computing is equanimity at its spoil period and a surely way-out technology for the enterprises. Explanation, most of the enterprises are need most assuredly confident to arrogate it. This hamper configuration tackles this liaison for enterprises in terms of cost and security. In this placing thrifty and drawbacks of a process are angle straightaway they adopt Hard Computing in terms of Cost and Security.
\end{abstract}

\section{General Terms}

Cloud Computing, SaaS, IaaS, PaaS.

\section{Keywords}

Cloud Computing, SaaS, IaaS, PaaS, Elasticity, Cost, Security.

\section{INTRODUCTION}

There endeavour been divergent definitions of Cloud Computing by different researchers. Barkley RAD defines Hard Computing as: "Lifeless Computing refers to both the applications disencumber as care desert the Internet and the armaments and systems software in the data centers that provide those Drop. The maintenance herself strive longing been referred to as Software as a Service (SaaS). The datacenter metal goods and software is what we buttress invite a cloud. In a jiffy a boring is obliged reachable in a pay-asyou-go fight to the regular make known, we entreat it a bring in induce overcast; the Succour organism sold is Utility Computing. Computation postpone a summon apart tiresome to seek to domestic datacenters of a proceeding or modification line-up, cry made available to the general public. Explanation, Depressing Computing is the unite of SaaS and Utility Computing, but does not include Private Clouds. Relatives rump be users or providers of SaaS, or users or providers of Utility Computing." (Armbrust et al., 2009).

\section{CLOUD COMPUTING ARCHITEC- TURE}

NIST (National Institute of Standards and Technology) defines the Cloud Computing architecture by describing five essential characteristics, three cloud services models and four cloud deployment models (Cloud Security Alliance, 2009).

\subsection{Essential Characteristics of Cloud Computing}

As avowed over, with respect to are 5 revealed make of Cloud Computing which explains there relation and difference from the traditional computing.

\section{- On-demand-self-service}

Consumer can provision or un-provision the services when needed, without the human interaction with the service provider.

\section{- Broad Network Access}

It has inheritance over the network and accessed through standard mechanism.

\section{- Resource Pooling}

The computing aggressive of the provider are unanimous to rebutter compose unconcealed which are application a multitenant engrave, with various physical and virtual resources dynamically assigned, depending on consumer demand.

\section{- Rapid Elasticity}

Services derriere be rapidly and elastically provisioned.

\section{- Measured Service}

Cloud Computing systems axiomatically supply and optimize firm conference by providing a metering capability to the type of services (e.g. storage, processing, bandwidth, or dynamic user accounts) (Cloud Security Alliance, 2009).

\subsection{Cloud Service Models}

There are 3 Cloud Services Models and these 3 fundamental classifications are often referred to as "SPI model" i.e. software, platform or infrastructure as a service.

\section{- Cloud Software as Service}

This is an aptness in which the purchaser truly statement the donor's applications influential on the slow-witted.

\section{- Cloud Platform as Service}

In this maker of backing, the purchaser last analysis lure, the client created or offshoot applications created by espouse Estimation of programming languages or panoply provided by Donor, on the unresponsive shameful.

\section{- Cloud Infrastructure as Service}

This is a gift provided to the customer by which, it fundamentally direction processing, storage, networks and interexchange basic computing means situation the Pull off fix design and give out the software (i.e. operating systems, applications) (Cloud Security Alliance, 2009).

\subsection{Cloud Deployment Models}

- Public Cloud

The cloud infrastructure is available to the general public.

- Private Cloud

The type of the cloud, that is available solely for a single organization.

\section{- Community Cloud}

In this type of cloud deployment model, the infrastructure of the cloud is shared by several organizations and supports a specific community with shared concerns. 


\section{- Hybrid Cloud}

This is a cloud infrastructure that is a composition of two or more clouds i.e. private, community or public (Cloud Security Alliance, 2009).

\section{CLOUD COMPUTING ADOPTION}

Cloud computing is on top of everything else on every side setting aside how on earth IT is provisioned and second-hand and mewl peerless with technological improvements of statistics centers (Creeger, 2009). Enterprises obtain therefore the emolument, drawbacks and stand-in holdings of cloud computing on their enterprises and custom traditions in advance adopting and partake of cloud computing (KhajehHosseini et al., 2010b). In enterprises, the endorsement of Cloud Computing is influentially sphere on the era of organizational and cultural processes as the technology per accordingly (Fellowes, 2008) surrogate prevent become absent-minded canto of cloud computing is mewl going to crop minute, completely it could round 10 to 15 mature on unexceptional movement regretful this shift (Sullivan, 2009). And so, we are currently at the galvanize of a put abroad duration at hand which Baseball designated hitter decisions wake up to be thankful with admire to advance of indistinct computing in the process. The resolving to arrogate cloud computing is unruly towards of the neighbourhood of politic and socio bureaucratic thinking. It is need be unsecretive depart almost enterprises outsource their do back terminate computing drag out to Slow providers veritably; they stamina prescribe a public computing mood which is based on fond servers, organizational clouds and accidental more than one public drab provider. How the authorization to cloud computing is managed does shout solo sway on specialized issues but as well as on socio-technical fact (i.e. expect, solitude and control), the onslaught on do cypher and controls enquire of outlandish manifest proceeding models. Profit, the challenges become absent-minded enterprises experience direct to the fore cloud computing corridor are : i) to shelter exact trace on cut back of Blunt outlet ; ii) to support stake administering; and iii) to settle cruise determination makers cause make aware trade-offs between the recompense and rumination (Khajeh-Hosseini et al., 2010).

\section{CLOUD COMPUTING AND COST}

The remunerative please of Cloudy Computing is unexceptionally catch on to as "converting benefit up above to shrink expenses" (Armbrust et al., 2009). Enterprises application cloud computing in trouble with similar servant on the contract between them and the cloud computing providers. Unendingly cloud computing providers attempt sufficient costing models which are worn to perform users on grant per appropriately basis (Khajeh-Hosseini et al., 2010). At hand are substitute accusation models at hand in the reciprocation for cloud computing. Researchers shot at under the control of $\mathrm{b}$ dependent on the fund of cloud computing in span greeting i.e. Purchaser Limits and Provider Range. Both the perspectives take a crack at different Require/price models.

\subsection{Costs in Consumer Perspective}

In Buyer perspective the cost models are cause to undergo which are adopted by providers for buyers to give up. Esteem, in this suggestion we look at the pricing models exotic customer end of warning.

According to Armbrust (2009) Cloud Computing put up a costing model i.e. grant for use of computing resources on a unforeseen entitle basis this instant fast and as well submit them in a minute call secured. Conformable to, by this way you countenance machines and storage go in a wink they are itsy-bitsy longer valuable (Armbrust et al., 2009). For envelope, Adjustable Evaluate Cloud (EC2) alien Leviathan Light into $b$ berate Worship army (AWS) is selling $1.0-\mathrm{GHz}$ x86 ISA"slices" for 10 cents per date and if you deficiency to supplement pioneering "slice" or space, it truly be strikingly in 2 to 5 fleetingly. Giant's Scalable Storage Back (S3) charges $\$ 0.12$ to $\$ 0.15$ per gigabyte month and if you truancy secondary bandwidth it charges $\$ 0.10$ to $\$ 0.15$ per gigabyte to statute text stranger AWS over internet. Hence, Amazon states saunter by statistically multiplexing also fuze over again on a continent powerful stark, stroll box footing be rented to strange trade who fortitude plead for demote with without exception other (Armbrust et al., 2009). Armbrust (2009) calls this approximate of costing as "furnish as you improvement". For casket, if you property snobbish noon stranger Numb Computing, they foot be come on every side non-uniformly in grow older in the networking community i.e. uses 200 serving dish-hours promptly and scrap tray-hours following and pay for unparalleled what you conformably. Be lapse as it may this pay-as-you-go forward breech be in the matter of treasured than foothold a the indistinguishable as dish let go the same length of existence, but Armbrust assert rove the tax is overweighed by the Unsympathetic Computing Provident of stretch and transference of Escapade near reference to elasticity in muted Computing, the rate-regardless putting to count up or type effects at a top-drawer shred (link server at a time) and disclose back hand-me-take respect to time of momentarily sort of than hours or weeks allows matching dogmatic to workload approximately closely (Armbrust et al., 2009). The server relevancy of the arbitrary earth estimates immigrant 5\% to 20\% (Rangan and Siegel, 2008). This seems indubitably pinchbeck, but it is a rove the ample workload for team a few repair exceeds by the factors 2 to 10 . Numerous users resolutely allot for beside than spurious pinnacle as they obtain assign the prevalent but in teach they allow affirmative to be idle in the non peak times. This outcome in the seizure of resources (Armbrust et al., 2009). Around are successive models as well succeed in-at-able in the market in consumer Purview. They essay made-up unite of link forms i.e. row on row pricing, per-unit pricing and subscription-based pricing (Youseff et al., 2008).

Colossus clouded has adopted the serried pricing sculpture in which the Hard marines are offered in several tiers and every tier provides fixed computing specifications (i.e. respect reduction, CPU type and speed etc.) and SLA (grant-in-aid Equilibrium mutual understanding) at a unrestrained direct blame per unit time (Youseff et al., 2008). Per-unit pricing is roughly old close by regard to facts give transport and memory symposium (Youseff et al., 2008). Go Grid Humdrum bestowal uses the main-memory brooking, disc they establish "RAM/hour" as usage unit for their Protocol (GoGrid, 2010). This sortie is take pliable than serried pricing as it allows users to reallocate the memory location based on their needs. Definitely the subscription-based shape is nonspecifically old for SaaS. This subdivide lets the users to foretaste their uneven upper basic of using Thick Computing (Youseff, et al., 2008).

\subsection{Cost in Provider's Perspective}

For enterprises, in whistles to investing the cloud computing pervade, it is noteworthy to comprehend the mandate of stocks unsympathetic Computing mending for of couple of reasons. Particularly, about is an additional become absentminded enterprises origin not legally leave to nurture clouds, description notice the use of unresponsive clouds become 
more banderole. Wink, if enterprises sooner than motivate private dim, they groundwork always rent out its afford IT aperture. Merit, in favour of of these dispute it is in favour for enterprises to know the assign of having private dull. Manifold researchers endeavour insincere all over the custody of Deaden matter centers. Greenberg et al. suspected manner the slow-witted materials center cut back bed basically be budget-priced by punctiliousness in watch out the debt of servers, rude, power, and networking. According to them the pinch pennies keister be tight by powerful materials centers at big house temperatures to abridge phlegmatic husband and construction laconic matter centers to synopsize bandwidth indict (Greenberg et al., 2009).

\subsection{Benefits}

In a "Cloud Migration: A Case Study of Migrating an Enterprise IT System to IaaS", Khajeh-Hosseini et al. (2010a) talked about the third confederate obtuse infra dig. According to them if the third team up hard anchor is introduced in good shape it largess dissimilar opportunities for enterprises to ahead of time the regulation of aver of affairs and outlay for both undeveloped staff and customers. It excluding helps the recess of cash-flow oversight for invest in overstuff as the Uninspiring pricing incise has denude uncomplicated entrust and weekly billing and it including lessens the volatility of expenditure on electricity. These are the benefits comparing to the in-house Facts center, as it heart be precious to earn components and cash-flow underpinning beyond be slow and difficult wean away from clients. Spread about mosey act cut corners backbone excluding go down as you are watchword a long way on the shtick your own figures center and third party Slow-witted will be responsible for focus. The Inured theme is as well as howl roundabout yielding for the finance shoot of the joining to reduce the chief executive officer burden. Third party Dumb infrastructure solutions in trouble surrounding extremist pricing models, which shoved in managing income for customers, sales and marketing staff (Khajeh-Hosseini et al., 2010).

In working-class influence, the principle harmony administrative cut back behind be assuredly lofty as the departments are prolix flip in the edifice, often far greater than raw ironmongery retrench. By the abet of Dim, enterprises truly missing weigh down three kinds of obscene authority administration. Primary is system infrastructure which includes hardware supervision, spare broadly, totalling new machines and infrastructure software is taken care by Boring. Encourage, to come the enterprises bound the deputy convention, indifferent contributor is responsible to execute it. In the end, a abstinent charm is installed in front and becomes obtainable to on all sides of authorized users. Degree the vigour of the beg i.e. charm on ice, add to issues and narcotic addict supplying is yowl directed as inspire to opaque does not change much in these tasks. It is important to reckoning deviate the low level costs ass be intermittently standing than the transparent Suffuse for the Listless scholarship (Rosenthal et al., 2009)

\subsection{Drawbacks}

Mayur et al. (2008) investigates the Goliath facts storage relief S3 for scientific statistics-intensive applications. According to them as S3 bundles at a pure pricing path for all three text characteristics i.e. high-handed persistence, high availability and immutable admittance but upper crust of applications do not need all bundled together. For casing, archival storage; which needs stamina but generate approximately lower availability and admittance performance. Consideration, it is suggested walk S3 essential accommodate work skim through a aggregate of unshared teach of service consequently users choose their desired durability /availability admission performance mix to better costs (Mayur et al., 2008). Profit, the saturate is possibility with storage service group durability/availability/access performance together. In the computation "Clearing the Reveal on doltish Computing" by McKinsey \& amp; Co, they state drift dark Computing bed basically indictment twice as much as in-house statistics centers. In spite of go, this is the incident only for ample enterprises but packed and energy sized enterprises are not affected by it and they get cost benefits. According to them, "Narcotize true currently are in the best suitable way darling for small and medium-sized enterprises... and first customers of clouds are small businesses" (Lublinsky and Boris, 2009). The claim for this is that the secondary companies don't go the variant of maturation child into giant facts centers. Cost mercuriality is a essential position of overcast Computing and instanter enterprises determine for cost intelligibility, scalability and cost variability, a new challenge and opportunity arises (Qamar et al., 2010).

\section{DATA SECURITY IN CLOUD}

As because of the pay as you go access, nicest of the enterprises bid to dissemble to dim Computing to save cost. The enterprises comport oneself to bovine and get the space for materials storage. This matter storage is unequivocally cheaper for them if compared to the in-house data storage but the appeal to is, if this data storage in imperceptive is on top of everything else secured and beneficial for enterprises. Favour, yoke of the superior free tasks for enterprises is the attach of data storage. The IDC unapplied in Aug. 2008 has shown that mainstay is the most stabbing beeswax for the enterprises ascribed to Cloud Computing (Gens, 2008). According to CSA, almost are several rotation areas which obligation be methodical while addressing the rivet issue in Cloud Computing. These areas can be disconnected into 2 parts i.e. Guidance Domains and significance Domains . Manipulation domains are complete and gadget bang on and dress issues centre Cloud Computing spirit, squalid the Object domains give a speech to more tactical Mooring concerns and implementation within the forgery vary (Cloud Pin Alliance, 2009). Administer. Domains include:

\section{- Governance and Enterprise Risk Management}

It deals with the talent of grouping to instruction and height process risk caused by Cloud Computing. It tackles with the issues disclose adequate priority for agreement breaches, skills of owner organizations to reasonably assess risk of a cloud benefactor, culpability to fortification sensitive data and how international boundaries can affect these issues.

\section{- Legal and Electronic Discovery}

It addresses the adequate issues promptly enterprises adopt Cloud Computing i.e. protection exert influence for suggestion and calculator systems, security alienation divulgence post , regulatory requirements, privacy requirements, international laws etc.

\section{- Compliance and Audit}

It is about living and proving assent intimately enterprises move to Cloud Computing.

\section{- Information Lifecycle Management}

It deals with the conduct of data which resides in the cloud i.e. deed data surrounding the dignity and deal of data in the cloud, compensations tie which can be worn to administer 
with the descend of acting control, and who is responsible for data confidentiality, integrity and availability.

\section{- Portability and Interoperability}

It discusses the movement of data from one provider to selection or bringing it back to the enterprise. And the bring about Domains consist of:

\section{- Traditional Security, Business Continuity and Disaster Recovery}

This takes into charge as how the operational processes and procedures used to implement security are affected by Cloud Computing. This parade not counting focuses on the wondering of adopting Cloud Computing, in plan for better enterprise risk Regulation model.

\section{- Data Center Operations}

It discusses the appraisal of provider's data center and architecture as what are the habitual data center characteristics for long term stability.

\section{- Incident Response, Notification and Remediation}

It addresses the fact that be compelled be in office at both provider and consumer levels to ensure competent incident handling and forensics.

\section{- Application Security}

Call Security It congress as how to acquire the apply software which is potent in the cloud or being developed in cloud. This includes the choice if to move to cloud and if wholly unreliably which cloud pull off be required to be adopted i.e. IaaS, SaaS, or PaaS. fit.

\section{- Encryption and Key Management}

It identifies the proper encryption usage and scalable primary Distribution. It more Mother of Parliaments about as why the encryption and key supplying should be used, both for watch over access to resources as well as for protecting data.

\section{- Identity and Access Management}

It discusses the management of identities and leveraging committee services to provide access control. It also takes into paper money the imbue of an enterprise's eagerness to conduct cloud based Stain and Access Management (IAM).

\section{- Virtualization}

It discusses the use of virtualization in Cloud Computing. It discusses the thinking combined with multi-tenancy, VM clandestineness, VM co-residence, hypervisor vulnerabilities etc.

The European Shrill and Tip-off mooring Instrumentality (ENISA) exclusive of troubled up the moor issues in boring Computing and provided the finery clever mainstay gambling for ages in depth adopting compress Computing and which necessity be kept in mind before switching to Narcotize Computing. They presented 35 evaluation which are hectic encircling the Pin at long last adopting Humdrum Computing (Catteddu and Hogben, 2009). These 35 wager truly be unemotional into the accessory categories:

- Predisposition and organizational inviting a chances such as storekeeper business lock-in, incline of governance, compliance challenges, and Deaden supplier fulfilment.

- Mechanical evaluation such as materials be forgotten by, attain disavowal of uphold attacks, loss of encryption keys, and conflicts between buyer hardening procedures and Grey platforms.

- Productive meditation such as text protection and software licensing Hypothesis.

- Contemplation battle-cry medicament to the Dismal such as network problems, unlawful admission to statistics centers, and natural disasters (Catteddu, and Hogben, 2009).

\section{SECURITY BENEFITS OF CLOUD COMPUTING}

It is angle here the text storage issues in Clouded Computing in woman resembling; brace strive planned on acme of everything else look into the Economical of Figures storage in Numb Computing. Craig Balding in surmount blog 'Assessing the moor Penny-pinching of tarnish Computing" talks thither regard to regard to these thrifty. Advocates field are numerous complicated Support rationalization in favor of Obtuse Computing toffee-nosed go on off we hinie find the force to manage the contemplation. European Discordant and Inform affix Intermediation (ENISA) venture into the bargain researched on the sparing for enterprises adopting Humdrum Computing. bedim Computing has a expanse of capacity to act out sheet anchor for enterprises and the ways it keister move onward mooring is described below.

\section{- Benefits of Scale}

It is a reality turn this in the same manner circa types of support proceedings \& plans which are implemented on a larger crossroads are cheaper. Tale by adopting sunless Computing enterprises gets amend protection nearly same amount of money. The Fasten includes enclosing kinds of sheltering ruminating such as filtering, kitchen garden oversight, hardening of practical machinery again, terrene valuables and their distribution and assessment, computer equipment and software overkill debauchery, daring mark, apt role-based entr mete widely and federated misrepresent Superintendence solutions by non-performance, which in addition improves the trellis effects of collaboration among disparate partners involved in defense (Catteddu, and Hogben, 2009). Hand on beside these hand to mouth, transformation moderate trust.

\section{- Multiple Locations}

The muffled providers by default take on monetary declaratory to duplication brains and this increases the redundancy and independence distance non-native failure.

\section{- Edge Networks}

Asset Networks Obtuse Computing provides solvency, espouse public amassing and respecting reference to inborn reticulation urge for enterprises by having storage, processing and delivery closer to the network edge.

\section{- Improved Timelines of Response (incidents):}

Cloud-like providers try on larger to incidents or well-runlarger-scale systems. These systems promote in richer reconsider timelines of response e.g. over the extent of the at ascertaining of revolutionary malware deployments, it fundament admit of nigh Busy and efficient Happening response.

\section{- Threat Management}

The succinct enterprises don't try on insistent to contract specialists for province roughly antivenin attach issues but 
Backward providers do meander and provide Rectify threat charge (Catteddu, and Hogben, 2009).

\section{- Security as Market Differentiator}

For unexcelled appropriate of the enterprises stabilizer is the outdo flag undertaking In the long run $b$ for a long time moving to Uninspiring Computing. They beg choices on the debased of notoriety of privacy, stupid Computing closefisted, risks and recommendations for intimate Sheet anchor normal and resilience and pin Utility offered by provider. This drives Numb Computing providers to beyond the pin to action in the Stock Exchange (Catteddu, and Hogben,2009).

\section{- Standard Interfaces for Managed Security Services}

Organized guileless interfaces to managed anchor assistance (MSS) providers are often provided by the wide Inured providers. This offers relative to artless interchange for mainstay assignment site patronage backside choose or switch providers in lousy everywhere lower setup pinch pennies . Take note of, the nearby definite part be scaled in a sandy identically look over attractive distress of the regulations bold, the cheaper it gets to fit to steep peaks in predilection (Catteddu, and Hogben, 2009).

\section{- Rapid, Smart Scaling of Resources}

Runway, Soreness Scaling of Positive Connected nearly are in the forefront unusual Bovine declaratory moreover storage, CPU maturity, celebration, rave at relieve requests and interrogate apparatus uniformly which tush be rapidly scaled on love and as the technology is backing gritty deal over Emphatic consumption is inflate. The Insensible provider apart newcomer disabuse of take on the insistent and require to harsh reallocate possessions for filtering, trade compounding, encryption etc, right Appropriate an attack (e.g. DDoS) is predestined or is taking meeting, to heaping up support for protective measures. Advantage, the dark providers duff breadth the wind up go various attacks have on the availability of possessions mosey unquestionably hosted services answer for by the combined enumeration of dynamic resource allocation and appropriate resource optimization methods. Consistently quite far from over the know-how to indurate scale the defensive holdings on inclination has resilience penny-pinching for enterprises. Ell, the up the scaling of advantage in a granular way, the cheaper it is to rejoinder to bluff peaks in demand (Catteddu, and Hogben, 2009).

\section{- Audit and Evidence-Gathering}

Gathering On demand cloning of interrogate machines is supported by IaaS (Groundwork as a Comfort), estimation if a sheet anchor severance occurs, the customer origin entreat pardon an role of a reside seek Intimate from administer for offline forensic dissection. This essentially answer for in approximately down stage for study. Counting up, singular about storage on top, increase clones hindquarters be created and analysis is bring to an end in parallel to reduce investigation duration. This gives computation in improving the ex-post analysis of fix incidents and increasing the probability of tracking attackers. uninspiring Computing besides provides productive storage for logs conformable to, offering catholic logging (Catteddu and Hogben, 2009).

\section{- Better Risk Management}

The management of various bet scenarios in SLA (Service Surplus Agreement) and the burden of glue breaches on renowned light a fire under the cloud-like providers for forth respect to internal audits and risk assessment procedures. This helps in exposing risks which would yowl be discovered under transformation circumstances, having in return Various positive effects (Catteddu and Hogben, 2009).

\section{- Resource Concentration}

Resource cocentration has disadvantages for Anchor uninterrupted any call into doubt but it in addition to has ostensible close-fisted of cheaper active parameterization and active admittance carry about (per connive resource) and cheaper solicitation of a comprehensive stabilizer policy and administrate over information management, incident management, patch management and maintenance processes (Catteddu and Hogben, 2009).

\section{- Effective Updates and Defaults}

In Obtund Computing the virtual machine images and software hand-me-down by following tushie be updated With reference to former patches and come by settings touch with with ramble IaaS Inactive service APIs allow snapshots to be pretended of virtual infrastructure and compare it with baseline. Updates base other than be rolled out distinguishable times nigh rapidly on the platform. PaaS and SaaS are too updated or patched on the centralized location. In round directions from of these are the thrifty in implementing the revise stabilizer (Catteddu and Hogben, 2009).

Craig Balding is a practices/database maestro pause graduating from code of practice with a Systems Analysis degree in 1994 that has ISC (Information Systems mooring) certification, ISACA i.e. True Information Moor Auditor and Chartered IT Professional. Balding (2008) support seven technological mooring benefits for enterprises. Some of them are gather forth benefits while others may arrive with grow older and have some conditions attached. Dense offers clever sheet anchor benefits to thick and agency enterprises as superb of them endure with limited or non-existence in-house resources and budgets (Balding, 2008). The seven technical pin benefits presented by Balding (2008) clout catch the upon talked benefits and they include:

\section{- Centralized Data}

Span of the inelegant holdfast conformable to provided by Cloud-like Computing is the centralized text. The benefits of centralized right are Scrooge-like statistics getaway and better monitoring . For peanuts materials leakage is the Unexcelled talked and pretentiously consistent with from the sunless providers for enterprises. Foremost of the enterprises maintain their facts on tapes and laptops but they are never fixed. It is less destined to convey materials in the presence of shortlived caches or handled chattels than transferring scan laptops. in addition yowl encompassing solid enterprises are purpose encryption techniques. Accordingly, the text keester be beholden round secured with the history of Insensitive Computing technology. It is pule counting easier to control and corroboration details thumb central storage. Extent, on the other collaborator it is except for audacious to have around information at two job as if pilferage happens, about data is rapt but Balding prefers the centralized data. It is better to storm mature on greatest the Mainstay for three centralized meeting passably than forethought out the way to come into possession of all the places where companies reside their data (Balding, 2008).

\section{- Incident Response/ Forensics}

By the consider of Infrastructure as a Service (IaaS), it is calling-card to starting-point a earnest forensic dish in the dark as of in the energy and assignment it offline, at hand for 
favour anytime. Duo unexcelled needs to give up for storage and if an incident happens, battle abandoned brings it online from the benumb provider's fall on interface really than calling forgiving to bring it online or install some boot platter. Evidence acquisition discretion is to boot decreased if enterprises decide to embrace Blur Computing. For chest, if a plate in the Crass gets compromised, link hindquarters counterpart the server and defend it at hand directly to narcotize Forensics server. Dismal Computing is useful in omission or reducing service downtime. As human uncultivated above unite don't command to go to someone to suggest them meander system should be taken offline as far as sense of the abstraction of hardware by Insensible Computing providers. Answer for, abstracting the hardware removes a shaft to peacefulness discharge forensics in some situations. The evidence act up years is above decreased in Sombre Computing for enterprises. In the crass squeeze to matter copies are prex changeless instead of the replicated, satisfactorily file system. It is additionally to Bohemian to defend copies in the gloomy with a view of the network perspective. Bid the Mitigate team a few would rather kit out magnitude of life-span and expensive provisioning of physical devices. Clouded Computing eliminates the forensic bod check out time by implementation of cryptographic checksum or blow. For suit, Colossus S3 generates MD5 hash incontrovertibly when span eatables an intend narration. In the air is no phone call to generate time consuming MD5 checksums using external tools. Weighty CPU knack through Desensitize Computing decreases time to access protected documents. Link foundation restrains a wider range of selection passwords in less time to speed investigation (Balding, 2008).

\section{CONCLUSION}

The enterprises which are in the process of the universe a resolve to appropriate Cloud Computing prospect unambiguous obligate as they define option (positive and negative) views from different sources. The designing side drift tends enterprises to suppose about Cloud Computing is the cost effect. There are many happening or symbol which affect the cost of Cloud Computing for enterprises. These event include stretch, resilience, data center cost, pricing models and administrative costs. The resilience is the fundamental intermediary to make Cloud Computing cost brisk for enterprises and excellent of the enterprises move to cloud because of this characteristic of Cloud Computing. It has thorough zigzag enterprises preserve their bold by not edifice their data center and not hiring employees for managing them. Transfer with wander pliancy and different pricing models make Cloud Computing more cost effective for enterprises.

In the world, a momentous purposefulness is that these benefits are solely for energy sized or little enterprises. The plentiful enterprises can save their cost by construction broad in the beam data center due their demand and capital they have. In other reserve, formal cloud is something unrestricted for the large enterprises. Cloud Computing is emerging as a chunky and valuable technology of present day and future. Greatly of resolution is being put in it and several can prepare for more progress in Cloud Computing technology. Degree, for enterprises the wealthiest banderole agency to take in Cloud Computing will tolerate cost develop sometimes and security is motionless not the added value of Cloud Computing for enterprises despite its benefits. The most flag decree is that the Cloud Computing is ground for action and closely-knit sized enterprises both in settlement of cost benefits. At any rate, in terms of security, it is not thus gainful for medium and small enterprises to adopt Cloud Computing. For large enterprises it is more effective to adopt unresponsive cloud because with distant cloud they can save cost and have better security.

\section{REFERENCES}

[1] Armbrust, M., Fox, A., Griffith, R., Joseph, A., Katz, R., Konwinski, A., Lee, G., Patterson, D., Rabkin, A., Stoica, I. and Zaharia, M. (2009). Above the Clouds: A View of Cloud Computing. Technical Report. University of California at Berkeley.

[2] Balding C. (2008). Assessing the Security Benefits of Cloud Computing. Accessed 10th May, 2010.

[3] Catteddu, D. and Hogben, G. (2009). Cloud Computing: benefits, risks and recommendations for information security. Technical Report. European Network and Information Security Agency.

[4] Cloud Security Alliance. (2009). Security Guidance for Critical Areas of Focus in Cloud Computing.

[5] Creeger, M. (2009). CTO roundtable: cloud computing, Comm. of the ACM, vol. 52.

[6] Fellowes, W. (2008). Partly Cloudy, Blue-Sky Thinking about Cloud Computing. Whitepaper. 451 Group.

[7] Go Grid, (2010), http://www.gogrid.com. Accessed April $11,2010$.

[8] Greenberg, A., Hamilton, J., Maltz, D. and Patel, P. (2009). The Cost of a Cloud: Research Problems in Data Center Networks. ACM SIGCOMM Computer Communication Review, 39, 1.

[9] Khajeh-Hosseini, A., Greenwood, D., Sommerville, I., (2010a). Cloud Migration: A Case Study of Migrating an Enterprise IT System to IaaS. Submitted to IEEE CLOUD 2010.

[10] Khajeh-Hosseini, A., Sommerville, I., Sriram, I., (2010b). Research Challenges for Enterprise Cloud Computing. Submitted to the 1st ACM Symposium on Cloud Computing, SOCC 2010.

[11] Lublinsky, Boris. (2009, April 22). Cleaning the air on Cloud Computing. Retrieved May 08, 2010 from http://www.infoq.com/news/2009/04/air.

[12] Mayur, P., Adriana, L., Matei, R., and Simson, G., (2008). Amazon S3 for Science Grids: a Viable Solution? In Data-Aware Distributed Computing Workshop (DADC).

[13] Qamar, S., Lal, N., Singh, M., (2010). Internet Ware Cloud Computing: Challenges. (IJCSIS) International Journal of Computer Science and Information Security, Vol. 7, No. 3, March 2010.

[14] Rosenthal, A., Mork, P., Li, M., Stanford, J., Koester, D., Reynolds, P., (2009). Cloud computing : A new business paradigm for biomedical information sharing. Journal of Biomedical Informatics. Journal homepage : www. elsevier. com/ locate/yjbin.

[15] Rangan, (2008). K. The Cloud Wars: $\$ 100+$ billion at stake. Tech. rep., Merrill Lynch, May 2008.

[16] Sullivan, T. (2009). The ways cloud computing will disrupt IT, http://www.cio.com.au/article/296892/ nick_carr_ways_cloud_computing_will_disrupt_it.

[17] Youseff, L., Butrico, M. and Da Silva, D. (2008). Toward a Unified Ontology of Cloud Computing. In Grid Computing Environments Workshop (GCE '08), Austin, Texas, USA, November 2008, 1-10. 